\title{
Excess smoking in malignant-phase hypertension
}

\author{
C ISLES, J J BROWN, A M M CUMMING, A F LEVER, D MCAREAVEY, J I S ROBERTSON, \\ V M HAWTHORNE, G M STEWART, J W K ROBERTSON, J WAPSHAW
}

pathy of diabetes ${ }^{4}$ are said to be commoner among smokers, though the second claim is disputed. ${ }^{5}$ Malignant-phase hypertension is characterised by another form of haemorrhagic retinopathy, ${ }^{6.7}$ but, as far as we are aware, the smoking habits of

\section{Summary and conclusions}

The smoking habits of 82 patients with malignant-phase hypertension were compared with those of subjects in three control groups matched for age and sex. Sixtyseven $(82 \%)$ of the patients with malignant-phase hypertension were smokers compared with $41(50 \%)$ and 71 $(43 \%)$ of the patients in two control groups with non-malignant hypertension, and 43 people $(52 \%)$ in a general population survey. The excess of smokers in the malignant-phase group was significant for men and women, together and separately, for cigarette smoking alone, and for all forms of smoking. There were no significant differences between the control groups. The chance of a hypertensive patient who smoked having the malignant phase was five times that of a hypertensive patient who did not. Twelve patients in the malignant-phase group had never smoked. All were alive three and a half years on average after presentation (range 11 months to seven years). Twenty-four $(36 \%)$ of the smokers with malignant-phase hypertension died during the same period. The mortality rate was significantly higher among patients with renal failure, as was the prevalence of smoking. Eighteen patients with malignant-phase hypertension had a serum creatinine concentration higher than $250 \mu \mathrm{mol} / 1(2.8 \mathrm{mg} / 100 \mathrm{ml})$; 17 were smokers and one an ex-smoker. Eleven of these 18 patients died.

It is concluded that hypertensive patients who smoke are much more likely to develop the malignant phase than those who do not, and that once the condition has developed it follows a particularly lethal course in smokers.

\section{Introduction}

Cigarette smoking predisposes to vascular disease in the heart, brain, and legs, ${ }^{12}$ and possibly also in the eye: occlusion of the retinal artery ${ }^{3}$ and the proliferative and haemorrhagic retino-

MRC Blood Pressure Unit, Western Infirmary, Glasgow G11 6NT

C ISLES, MB, CHB, resident (present appointment: medical registrar, Dumfries Royal Infirmary, Dumfries)

J J BROWN, MB, FRCP, consultant physician

A M M CUMMING, RGN, clinical nursing officer

A F LEVER, MB, FRCP, consultant physician

D MCAREAVEY, $M B$, CHB, senior house officer

J I S ROBERTSON, MB, FRCP, consultant physician

MMR Cardiorespiratory Screening Unit, Glasgow G2

V M HAWTHORNE, MD, FRCPGLAS, professor and chairman, department of epidemiology, University of Michigan, USA

G M STEWART, $M B$, CHB, research assistant

Western District Medical Computer Department, Western Infirmary, Glasgow

J W K ROBERTSON, BSC, PHD, systems and programming manager

Glasgow Blood Pressure Clinic, Glasgow

J WAPSHAW, MB, CHB, medical assistant malignant-phase and non-malignant hypertension. Colleagues in Birmingham have conducted a parallel study. ${ }^{8}$

\section{Subjects and methods}

A smoker was defined as a person who habitually smoked cigarettes, a pipe, or cigars within two months of presentation, which, when possible, was taken as the date of first admission to our wards. By definition, therefore, all other patients were either ex-smokers or had never smoked. We compared the smoking habits of four groups of people.

Group $A$-The case notes of all patients with malignant-phase hypertension admitted to the wards of the blood-pressure unit between 1967 and 1978 were examined. Information was recorded on the following aspects at presentation: age, occupation (of men), smoking habits, blood pressure, appearance of the retinae, treatment, and serum creatinine concentration. The clinical state in 1978 was also assessed. Eighty-two patients qualified for inclusion, ${ }^{7}$ having increased arterial pressure and bilateral retinal haemorrhages and exudates; 41 had bilateral papilloedema as well. The retinae were photographed in 49 cases and in each the ophthalmoscopic findings were confirmed. Hypertensive patients with diabetes or retinal artery occlusion were excluded from the analysis. Two patients with malignant-phase hypertension were excluded because their smoking habits had not been recorded. The group therefore comprised 39 men (mean age 44.9 years) and 43 women (mean age 42.8 years), who had an average arterial pressure of $231 / 145 \mathrm{~mm} \mathrm{Hg}$ when first seen on the ward. Sixty-seven $\left(82^{\circ}\right)$ were smokers, three were ex-smokers, and 12 had never smoked. There were no significant differences in arterial pressure when those who had already started treatment were compared with those who had not, reflecting that the treatment period before admission was invariably brief.

Group B-We obtained information in the same way from the case notes of 126 patients with non-malignant hypertension who had been admitted to our wards during the same period as the index group. The criteria for "non-malignant" and "benign" hypertension are the same, but the former term is preferable since the condition is not benign. ${ }^{7}$ Eighty-two patients were individually matched for age ( \pm 2 years) and sex with the 82 patients in the malignant phase. None had haemorrhages, exudates, or papilloedema in either retina. The mean arterial pressure for the matched group was $190 / 119 \mathrm{~mm} \mathrm{Hg}$.

Group C-A second control group of hypertensive patients not in the malignant phase was obtained from the Glasgow Blood-Pressure Clinic. ${ }^{9}$ Information on arterial pressure, treatment, and smoking habits was extracted from the computer records of 438 men and 455 women. Two of these controls were matched for age $( \pm 1$ year in all except one patient) and sex with each patient in the malignant phase. The mean blood pressure for the matched group was $173 / 117 \mathrm{~mm} \mathrm{Hg}$.

Group D-Data for a third control group were obtained from a computer file holding information on the blood pressure, smoking habits, and other characteristics of 13009 people examined between 1974 and 1976 during the course of a local epidemiological survey. ${ }^{10}$ Each patient with malignant-phase hypertension in group $\mathrm{A}$ was matched by computer with a person of the same age and sex from this general population. No attempt was made to exclude people with disease, including hypertension, since this was a "general" not a normal population. The average arterial pressure in the matched group was $144 / 84 \mathrm{~mm} \mathrm{Hg}$.

In none of the control groups were the smoking habits of the patients who were matched significantly different from those of the population from which they were derived. 


\section{Results}

Proportions of smokers in each group-Sixty-seven $\left(82^{\circ}{ }_{0}\right)$ of the patients with malignant-phase hypertension were smokers compared with $41(50 \%), 71(43 \%)$, and $43\left(52^{\circ}{ }_{0}\right)$ in the three matched control groups $\mathrm{B}, \mathrm{C}$, and $\mathrm{D}$, respectively. Differences between the malignantphase and control groups were significant for both sexes separately and together, for all forms of smoking combined, and for cigarette smoking alone. There were no significant differences between the three control groups nor was there a large difference between control groups and results of a national survey of smoking habits in 1975 performed by the Tobacco Research Council ${ }^{11}$ (table I). The chance of a smoker having malignant hypertension was between three and five times that of a non-smoker. This was assessed by Odd's ratio, comparing data on patients with malignant-phase hypertension with those from different control groups (table II). Because smoking varies with social class ${ }^{11}$ it was important to ensure that classes 4 and 5 (Registrar General's classification) were not overrepresented among patients with malignant hypertension since this would tend to raise the proportion of smokers within the group. No influence of this sort was apparent. Social classes 4 and 5 contributed $13(16 \%)$ of the patients in each of groups A and B.

Mortality-Malignant-phase hypertension is characterised by renal failure and high mortality as well as retinopathy. Among patients with malignant-phase hypertension, smokers seem to fare worse in both respects: of the 12 patients in this group who had never smoked, all were alive 3.42 years on average after presentation (range 11 months to seven years). Among the 67 smokers, on the other hand, 24 deaths $\left(36^{\circ}\right.$ mortality) occurred within a mean of 3.97 years, a significantly higher mortality $(P<0.01$, Fisher's exact test). Although the smokers had a marginally lower average blood pressure at presentation (228/146 compared with $238 / 151 \mathrm{~mm} \mathrm{Hg}$ in non-smokers), a factor favouring survival, their slightly higher average age (44.4 compared with 38.7 years) and longer follow-up would have had the opposite effect. Even in combination, however, these factors are insufficient to account for the excess mortality among patients with malignant-phase hypertension who smoke. No such difference was apparent in the patients in group B: one of the smokers $(2.4 \%)$ and none of those who had never smoked died during the same period.

Renal failure-Fifty-two $\left(63^{\circ}{ }_{0}\right)$ of the patients in the malignant phase had raised serum creatinine concentrations (upper limit of normal $115 \mu \mathrm{mol} / 1(1.3 \mathrm{mg} / 100 \mathrm{ml}))$. The average serum creatinine concentration was $106 \mu \mathrm{mol} / 1(1.2 \mathrm{mg} / 100 \mathrm{ml})$ for the 12 malignantphase patients who had never smoked. The concentration in the 67 smokers in the group was $224 \mu \mathrm{mol} / 1(2.5 \mathrm{mg} / 100 \mathrm{ml}) \quad(t=2.28$; $\mathrm{P}<0.05)$. Eighteen patients $(22 \%$ of the total) had creatinine concentrations of over $250 \mathrm{umol} / \mathrm{l}(2.8 \mathrm{mg} / 100 \mathrm{ml})$, and of these, 17 were smokers. The one exception was an ex-smoker. Eleven of these 18 patients $(61 \%)$ died. By comparison only seven $(9 \%)$ of the patients in group B had abnormal renal function.

Thus smoking was commoner among patients with malignant-phase hypertension; smokers with malignant-phase hypertension were more likely to have renal failure; those with renal failure were more likely to die; and those who died were more likely to have been smokers.

\section{Discussion}

Several potential sources of error and bias exist in a retrospective analysis of this sort. Smoking varies year by year and with age, sex, and social class. ${ }^{11}$ Our data for groups A and B, however, were contemporary; age and sex were matched in all groups and there was no important difference in social class between groups $\mathrm{A}$ and $\mathrm{B}$. The smoking habits of patients in the
TABLE II-Odd's ratios showing increased risk of smokers having malignant hypertension compared with non-smokers in control groups

\begin{tabular}{|c|c|c|c|}
\hline & & $\underset{\text { (non-malignant }}{\text { Groups } B \text { and } C}$ & $\begin{array}{l}\text { Group } \mathrm{D} \text { (general } \\
\text { population) }\end{array}$ \\
\hline $\begin{array}{l}\text { All forms of smoking } \\
\text { Cigarette smoking only }\end{array}$ & $\begin{array}{ll}\ldots & \ldots \\
\ldots & \end{array}$ & $\begin{array}{l}5 \cdot 4 \times \\
4 \cdot 4 \times\end{array}$ & $\begin{array}{l}4.1 \times \\
3.3 \times\end{array}$ \\
\hline
\end{tabular}

blood-pressure unit (groups $\mathrm{A}$ and $\mathrm{B}$ ) were recorded by clinicians who were unaware that an analysis would be done later. This avoided some observer bias, but had the disadvantage that data were not recorded in a standardised way. While random variation from this source is possible, a systematic error is unlikely since data were collected by the same clinicians in the same wards during the same period. Information was collected in a standardised fashion in the Glasgow Blood-Pressure Clinic (group C) and the local population survey (group D). No large or significant differences emerged between the three control groups (B, C, and D), and data from a national population survey were similar to those from control groups (table I).

The main finding of our study, therefore, was a large excess of smokers among patients with malignant-phase hypertension. The excess is a feature of the malignant phase, not of hypertension generally. Bloxham $e^{2} a^{8}$ report a similar finding. Their criteria of the malignant phase (bilateral retinal haemorrhages or exudates) were slightly different from ours (bilateral retinal haemorrhages and exudates). We also showed that hypertensive patients who smoke are five times more likely to be in the malignant phase than hypertensive patients who do not smoke. We had insufficient information to determine whether the number of cigarettes smoked was important.

The pharmacological effect of smoking a single cigarette is to raise blood pressure acutely, ${ }^{12}$ but clinical and epidemiological studies show either no relation or an inverse relation between smoking and blood pressure. ${ }^{13-16}$ Malignant-phase hypertension was not identified separately in these reports.

There are three main explanations for an association between smoking and disease. A disease may encourage patients to smoke; smoking may predispose to a disease; or a third agent may, separately, predispose to a disease and encourage patients to smoke. These issues have been extensively debated, and most investigators now agree that smoking predisposes to, causes, or accelerates several important vascular diseases. ${ }^{12} 16$ The same questions arise here: does excess smoking predispose to malignant hypertension; does the disease encourage patients to smoke; or is there a third agent encouraging both ? We know of no evidence favouring the second or third possibility. If the second were true, more than a quarter of our patients would have had to begin smoking for the first time in the usually brief interval between the abrupt onset of malignant-phase hypertension and the recording of smoking habits. This was not seen in the patients with non-malignant hypertension admitted to the same ward and given similar treatment.

We think it more likely that smoking predisposes to the development of the malignant phase in a patient who is already hypertensive. This may explain the higher mortality from hypertension among smokers. ${ }^{2}$ Clearly smoking is not the only cause of malignant-phase hypertension; some of our patients had never smoked. Nor is it likely to be the primary cause. Most workers, including ourselves, agree that increased

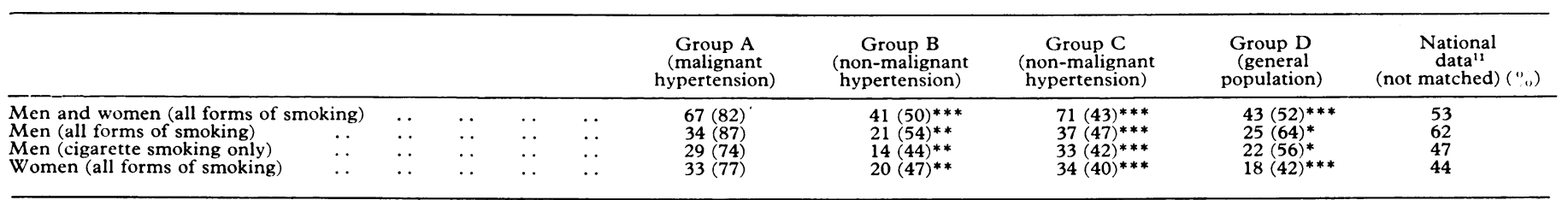


arterial pressure is the primary cause.$^{6} 1 ; 18$ We have suggested that increased arterial pressure acts by damaging blood vessels and promoting intravascular coagulation, which is responsible for the main features of the disease. Smoking could have its effect at this stage of the process, since it increases platelet stickiness, ${ }^{19}$ the viscosity of blood, ${ }^{20}$ and the likelihood of arterial thrombosis. ${ }^{1}$

In the group with malignant hypertension mortality was higher among smokers. Increased mortality would be expected in any group containing a high proportion of smokers, but a $36^{\circ}{ }_{0}$ mortality rate over four years in a group with a mean presenting age of 44 years is more than could be expected from this alone. The mortality rate among smokers with nonmalignant hypertension was only $2 \cdot 4^{\circ}{ }_{0}$ during the same period. Smoking was also related to renal failure, and, as would be expected, ${ }^{6}$ renal failure was related to a fatal outcome. This raises the possibility that smoking predisposes to malignant hypertension and to a fatal outcome from renal failure. The two effects are not necessarily independent. The characteristic vascular abnormality of malignant-phase hypertension in the kidney is the same as that in other susceptible organs. The intravascular coagulation in the malignant phase, which may be produced by smoking, is particularly pronounced within the kidney.

People who stop smoking are less likely to develop vascular disease. Those with vascular disease decrease the chance of further complication when they stop smoking. ${ }^{1216}$ On the evidence presented here we believe that patients with hypertension should be advised to stop smoking. At worst their chance of developing cancer and several important vascular diseases will be reduced when they stop; at best there may be additional protection from malignant-phase hypertension, a particularly lethal form of vascular disease.
We thank Miss Ann Matheson and Miss Anne Glencross for secretarial help; Mrs W Lawrence for programming; Mrs Mary Smalls and Mrs Helen Watt for statistical advice; and Miss I $\mathbf{M}$ McBride and the staff in the records department for their efforts in locating case notes.

\section{References}

${ }^{1}$ Royal College of Physicians, third report, Smoking or Health ? London, Pitman Medical, 1977.

2 Doll, R, and Peto, R, British Medical fournal, 1976, 2, 1525.

${ }^{3}$ Ellis, C J, et al, British Medical fournal, 1964, 2, 1093.

4 Paetkau, M E, et al, Diabetes, 1977, 26, 46.

5 West, H M, and Stober, J A, Lancet, 1978, 1, 49.

${ }^{6}$ Pickering, G W, in High Blood Pressure. London, Churchill, 1968.

7 World Health Organisation, Technical Report, Series No 628. Geneva, WHO, 1978.

${ }^{8}$ Bloxham, C A, Beevers, D G, and Walker, J M, British Medical fournal, $1979,1,581$

9 The Glasgow Blood Pressure Clinic, Fournal of the Royal College of Physicians, 1972, 7, 87

${ }^{10}$ Hawthorne, V M, Current Medical Research Opinion, 1977, 5, suppl No 1 , p 109.

$11 \mathrm{P} N$ Lee, Research Paper I, Statistics of Smoking in the UK, 7th edn. London, Tobacco Research Council, 1976.

12 Cellina, G U, Honour, A J, and Littler, W A, American Heart fournal, $1975,89,18$.

13 Ballantyne, D, Devine, B L, and Fife, R, British Medical fournal, 1978, 1,880 .

${ }^{14}$ Reid, D D, Holland, W W, and Rose, G A, Lancet, 1967, 2, 1375.

15 Seltzer, C C, American Heart fournal, 1974, 87, 558.

${ }^{16}$ Ball, K, and Turner, R, Lancet, 1974, 2, 822.

17 Beilin, L J, and Goldby, F S, Clinical Science and Molecular Medicine, 1977, 52, 111

18 Gavras, H, et al, Kidney International, 1975, 8, suppl No 5, p 254.

19 Levine, P H, Circulation, 1973, 48, 619.

${ }^{20}$ Dintenfass, L, Medical fournal of Australia, 1975, 137, 435.

(Accepted 8 fanuary 1979)

\title{
Malignant hypertension and cigarette smoking
}

\author{
C A BLOXHAM, D G BEEVERS, J M WALKER
}

British Medical fournal, 1979, 1, 581-583

\section{Summary and conclusions}

The smoking habits of 48 patients with malignant hypertension were compared with those of 92 consecutive patients with non-malignant hypertension. Thirty-three of the patients with malignant and 34 of the patients with non-malignant hypertension were smokers when first diagnosed. This difference was significant, and remained so when only men or black and white patients were considered separately.

Results suggest that malignant hypertension is yet another disease related to cigarette smoking.

\section{Introduction}

Epidemiological and clinical studies have consistently failed to show any relation between cigarette smoking and hypertension. ${ }^{1-3}$

\footnotetext{
University of Birmingham, Department of Medicine, Dudley Road Hospital, Birmingham B18 7QH

C A BLOXHAM, MB, MRCP, research fellow

D G BEEVERS, MB, MRCP, senior lecturer

J M WALKER, MB, MRCP, research fellow
}

The present study was prompted by a clinical impression of a higher incidence of cigarette smoking among patients with malignant-phase hypertension when compared with those with non-malignant hypertension, and a report of an association between cigarette smoking and diabetic retinopathy. ${ }^{4} \mathrm{We}$ therefore analysed the smoking habits of all patients with malignant-phase hypertension admitted to this hospital over the past six years and compared them with 92 consecutive patients with non-malignant hypertension who were attending the blood-pressure clinic at this hospital. A similar and parallel study was conducted by colleagues in Glasgow. ${ }^{5}$

\section{Patients and methods}

We obtained the case records of 48 consecutive cases of malignantphase hypertension admitted to this hospital during 1972-8. The criterion for inclusion in this group was the presence of bilateral retinal haemorrhages or exudates with or without papilloedema. As this analysis was conducted retrospectively by examining the notes we could include only cases whose ICD diagnostic code was 400 (malignant or accelerated hypertension). Notes were checked to ensure that the retinal changes had been recorded. Patients with renal disease were not excluded; four patients had chronic pyelonephritis and one congenital hypoplastic kidneys. One patient had current phaeochromocytoma; the remainder had essential hypertension. Of the 48 patients, 16 had a serum urea concentration above $10 \mathrm{mmol} / \mathrm{l}$ $(60 \mathrm{mg} / 100 \mathrm{ml})$. The series included six diabetics (fasting blood glucose $>6.5 \mathrm{mmol} / 1(>117 \mathrm{mg} / 100 \mathrm{ml})$ ), of whom four smoked; 